\title{
TENUN DAN PENERAPANNYA \\ PADA DESAIN INTERIOR SEBAGAI WARISAN BUDAYA YANG MEMILIKI NILAI JUAL YANG TINGGI
}

\author{
Grace Hartanti \\ Jurusan Desain Interior, Fakultas Komunikasi Multimedia, Bina Nusantara University \\ Jl. K.H. Syahdan No. 9, Palmerah, Jakarta Barat 11480 \\ gracehartanti@yahoo.com
}

\begin{abstract}
Weaving is one of the traditional fabric cultural arts of Indonesia produced in various regions across the archipelago (Sumatra, Kalimantan, Bali, Sulawesi, Lombok, Sumbawa, etc.). Weaving has a significance, historical value, and high technique both in terms of colors, patterns, materials and type of yarn used and each region has the characteristics of each. Weaving as one of high cultural heritage (Heritage) is the pride of Indonesia which may reflect national identity. Therefore, weaving both in terms of production engineering, design and the resulting product should be maintained and preserved its existence, and promoted for reuse. One of them in the world of interior design can be used as an aesthetic element to promote local cultural elements (local content) of Indonesia.
\end{abstract}

Keywords: weaving, local content, the application of weaving in interior design

\begin{abstract}
ABSTRAK
Tenun merupakan salah satu seni budaya kain tradisional Indonesia yang diproduksi di berbagai wilayah di seluruh Nusantara (Sumatera, Kalimantan, Bali, Sulawesi, Lombok, Sumbawa, dll). Tenun memiliki makna, nilai sejarah, dan teknik yang tinggi baik dari segi warna, motif, jenis bahan dan benang yang digunakan serta tiap daerah memiliki ciri khas masing-masing. Tenun sebagai salah satu warisan budaya tinggi (heritage) merupakan kebanggaan bangsa Indonesia yang dapat mencerminkan jati diri bangsa. Oleh sebab itu, tenun baik dari segi teknik produksi, desain dan produk yang dihasilkan harus dijaga dan dilestarikan keberadaannya, serta dimasyarakatkan kembali penggunaannya. Salah satunya dalam dunia desain interior yang dapat digunakan sebagai elemen estetis untuk mengedepankan unsur-unsur/budaya lokal (local content) Bangsa Indonesia.
\end{abstract}

Kata kunci: tenun, local content, penerapan tenun pada desain interior 


\section{PENDAHULUAN}

Apabila ada orang yang menyebutkan Pandai Sikek, umumnya teringat dengan songket. Pandai Sikek sudah identik dengan songket. Orang Pandai Sikek sendiri tidak menyebutnya songket tetapi tenun, sebab yang dimaksud adalah benang katun dan benang mas yang ditenun dengan tangan, diatas alat yang bernama panta sehingga menjadi kain, kain balapak atau kain bacatua yang dipakai pai baralek, yaitu pada pesta perkawinan.

Bagi orang Minangkabau, yang menyebut diri mereka sebagai orang yang beradat, kain tenun adalah bagian yang tidak bisa dipisahkan dari upacara-upacara adat istiadat, mulai dari yang dipakai sebagai sarung dan selendang, sebagai tingkuluk dan tokah bagi perempuan, dan sebagai sisamping, salempang dan cawek bajambua bagi laki-laki.

Kain tenun juga diberikan sebagai tando pada upacara adat pertunangan dan pada waktu kusuik ka disalasaikan-karuah ka dipajaniah. Selain itu kain-kain tenun yang menjadi koleksi suatu kaum akan dipajang pada seutas tali yang direntangkan diantara tiang-tiang utama rumah yang baru melaksanakan upacara batagak rumah gadang.

Sesuai dengan bergulirnya roda waktu, dimana terdapat usaha dari berbagai pihak untuk melestarikan dan memperkenalkan kembali budaya lokal bangsa baik kepada masyarakat Indonesia sendiri ataupun kepada mancanegara, maka budaya lokal yakni kain tenun mulai diterapkan kembali. Baik dari desain fashion yang menerapkan kain tenun dengan perancangan pakaian tradisional dan modern; desain grafis dengan marketing komunikasinya yang mengangkat corak dan motif kain tenun; hingga desain interior yang mengangkat kembali budaya memajang koleksi kain tenun serta penerapannya pada elemen-elemen interior seperti ceiling, dinding, lantai, dan furniture baik sebagai suatu fungsi ataupun sekedar pemanis/estetis dalam sebuah ruang.

\section{PEMBAHASAN}

\section{Sejarah Tenun}

Tidak ada sejarah yang pasti tentang kapan tenun songket mulai dikembangkan di Minangkabau atau di Pandai Sikek. Akan tetapi kepandaian menenun tentu sudah dibawa oleh nenek moyang kita bangsa Austronesia atau yang disebut juga Malayo-Polynesia, dari Tanah Asal, ketika terjadi migrasi besar-besaran penduduk dari daratan Asia ke arah Selatan dan Timur beberapa ribu tahun yang lalu, bersamaan dengan segala kepandaian yang esensial untuk kehidupan, seperti kepandaian becocok tanam, kepandaian membuat dan menggunakan alat-alat pertanian, pertukangan, senjata, dan sebagainya. Sesuai dengan fitrah manusia, kepandaian dasar pertukangan tentu mengalami pengkayaan estetika sehingga menjadi apa yang sekarang dikenal dengan istilah kerajinan, dan kemudian menjadi seni. Hal ini sejalan dengan perkembangan di bidang ekpresi lainnya seperti seni gerak, seni suara dan seni pementasan. Sebagai warisan demikian, tenun bisa dikatakan sama umurnya dengan stelsel matrilinial orang Minang, terukaan sawah di Luhak nan Tigo, dan budaya lisan Kato Pusako pepatah petitih.

Di sini juga kita menemukan kesamaan rumpun Austronesia pada kain tenun Sumatra pada umumnya dengan seluruh kain tenun Nusantara hingga ke Sumba dan Timor, juga dengan tenunan La Na di Thailand Utara dan Laos. Rumpun ini akan memecah nanti dilihat dari segi kahalusan motif setelah masuknya kebudayaan India dan Cina dari Utara. Akan tetapi kesamaannya bertahan di segi peralatan tenun dan teknik bertenun. 
Beberapa ratus tahun yang lalu, di hulu sungai Batanghari, yang disebut Sungai Dareh, berkembang suatu pemukiman dan pusat perdagangan yang makmur. Penduduk dari daerah yang sekarang disebut Alam Surambi Sungai Pagu, dan dari daerah-daerah yang lebih ke Utara lagi, datang ke tempat ini untuk menjual hasil-hasil alam berupa rempah-rempah dan emas. Daerah ini dikunjungi pula oleh pedagang-pedagang yang datang dari seberang laut, dari India dan Cina. Kaum wanita di daerah ini memakai pakaian yang lebih cantik bagi ukuran masa itu, istilah sekarang: lebih fashionable.

Daerah ini kemudian terkenal dengan nama kerajaan Darmasyraya. Inilah cikal-bakal kebudayaan Melayu. Bertahun-tahun daerah ini menjadi titik pertemuan ekonomi dan budaya antara kebudayaan-kebudayan yang sudah lebih kaya dan maju di Utara, Cina, Mongol dan India, dengan budaya lokal. Dalam kurun beberapa puluh tahun itu, atau mungkin sampai dua ratus tahun, setelah mengalami pergantian raja-raja dan penguasa, penduduknya menyerap banyak ilmu dan teknologi dari bangsa asing, disamping kemajuan bidang ekonomi dan politik yang memperkaya dan meningkatkan mutu kebudayaan lokal. Diantara kemajuan yang dialami adalah dalam bidang pakaian dan teknik bertenun, beserta pengkayaan corak motif dan bahan-bahan yang dapat dipergunakan.

Kalau sebelumnya, sesuai dengan perkembangan masyarakat, orang membuat pakaian dari benang yang dibuat dari bahan-bahan yang tersedia di tempat pemukiman mereka, seperti serat kulit pohon, dengan perkembangan perdagangan orang-orang India memperkenalkan bahan dari serat kapas dan linen, juga benang yang disalut dengan lempengan emas tipis. Pedagang Cina membawa benang sutra yang berasal dari kepompong ulat sutra, juga benang yang dibungkus dengan emas kertas kemudian dikenal dengan nama emas prada sehingga bisa diperkirakan bahwa pedagang India pun banyak memperdagangkan bahan tersebut.

Pada tahun 1347 Adityawarman memindahkan pusat kerajaan dan kebudayaan Melayu dari Darmasyraya ke Pagaruruyung, dan kawasan di sekitar Gunung Merapi dan Gunung Singgalang yang pada waktu itu terdiri dari Luhak nan Tigo dan Rantaunya yang Tujuh Jurai, menjadi terkenal sebagai Alam Minangkabau, dengan beberapa pusat pemerintahan yang tersebar di Pariangan, Sungai Tarok, Limo Kaum, Pagaruryung, Batipuh, Sumanik, Saruaso, Buo, Biaro, Payakumbuh, dan lain-lain.

Alam Minangkabau dengan falsafah alam yang dianut masyrakatnya, alur dan patut serta alam takambang jadi guru, sangat memberi peluang bagi tumbuh dan berkembangya kebudayaan dan kesenian dengan pengkayaan dari unsur-unsur budaya asing. Susunan masyarakat yang bersuku-suku eksogami dan, yang lebih utama lagi, aturan sumando manyumando, telah mengeliminir konflik antar kelompok sehingga kedamaian dapat terwujud dalam jangka waktu yang panjang dan memberi kesempatan bagi anak nagari untuk memperlajari dan memperhalus ilmu-ilmu dan keterampilan termasuk keterampilan bertenun.

Daerah Batipuh sebagai salah satu pusat pemerintahan, kedudukan Tuan Gadang Batipuh sebagai Harimau Campo Koto Piliang, dapat diduga menjadi salah satu daerah yang amat penting pada masa kejayaan Minangkabau dahulu, bersama daerah-daerah lain yang tersebut diatas. Sejalan dengan keadaan itu, masyarakatnya tentu mandapat kesempatan yang lebih banyak pula untuk melakukan kegiatan ekonomi dan budaya termasuk keterampilan tenun sehingga mutu dan corak kain tenun semakin tinggi dan halus. Gadis-gadis menenun kain sarung dan tingkuluk dengan benang emas untuk dipakai ketika mereka menikah, dan perempuan lainnya menenun kain untuk dijual.

Adat istiadat di Minangkabau mendorong kegiatan bertenun ini lebih jauh lagi karena pada setiap kesempatan upacara adat, kain tenun selalu wajib dipakai dan dihadirkan. Kata-kata adat dinukilkan di dalam nama-nama motif sehingga menjadi buah bibir dan diucapkan setiap saat. Kain tenun menjadi pakaian raja-raja, datuk-datuk dan puti-puti. Dimasa inilah, dimasa kejayaan Turki Usmani dan Asia Tengah, pada puncak kebesaran Dinasti Mongol di India ketika Sultan Akbar, 15561605 sangat memajukan seni dan ilmu pengetahuan, pada masa kejayaan Dinasti Ming dan Manchu di 
Cina; ketika itu pertukaran perdagangan dan budaya sedang sangat pesat dan melibatkan Minangkabau sebagai suatu kawasan yang menjadi lintasan perdagangan dan juga negeri yang mempunyai komoditi dagang yang penting yaitu rempah-rempah dan emas, seni menenun kain dangan sutra dan benang emas di Sumatra, bersamaan dengan suji dan sulaman pun mencapai puncak kemajuannya dan menemukan ciri khasnya tersendiri.

Hampir semua pelosok Minangkabau, dari Luhak sampai ke rantau, mempunyai pusat-pusat kerajinan tenun, suji dan sulaman. Masing-masih mengembangkan corak dan ciri-cirinya sendiri, hal yang sangat dikuasai oleh para pedagang barang antik dan kolektor. Beberapa nagari yang terkenal sekali dengan kain tenununya dan sangat produktif pada masa itu adalah Koto Gadang, Sungayang, dan Pitalah di Batipuh, dan nagari yang melanjutkan tradisi warisan menenun hari ini adalah nagari yang termasuk Batipuh Sapuluh Koto juga yaitu Pandai Sikek.

Motif-motif kain tenun Pandai Sikek selalu diambil dari contoh kain-kain tua yang masih tersimpan dengan baik dan sering dipakai sebagai pakain pada upacara-upacara adat dan untuk fungsi lain dalam lingkup upacara adat, misalnya sebagai tando dan dipajang juga pada waktu batagak rumah.

Motif-motif tenun Pandai Sikek diyakini sebagai motif asli pada kain-kain tenunan perempuan-perempuan Pandai Sikek pada zaman lampau, yang namanya sebagian masih diingat oleh beberapa orang tua yang hidup sekarang. Diantara mereka adalah:

- Sari Bentan, Namun, Salamah di Baruah

- Nuriah, Ipah, Pasah, Nyiah dan Jalisah di Tanjung

Ada kira-kira sepuluh orang master tenun di Pandai Sikek pada zaman atau generasi namanama diatas, kira-kira seratus tahun yang lalu. Ada juga beberapa wanita Pandai Sikek zaman dahulu yang dikenal dengan nama julukan yang berhubungan dengan peralatan tenun. Misalnya, dikenal :

- Inyiak Makau di Tanjuang

- Inyiak Suri di Koto Tinggi

- Inyiak Banang, dan Inyiak Karok

Disamping itu, Pandai Sikek, sebagai "center of excellece" di bidang tenun songket waktu itu, tentu wanita-wanitanya ada mengerjakan tenun pesanan dari daerah-daerah lain seperti dari Pitalah di Batipuah, Koto Gadang di Agam dan dari Sungayang dengan corak benang dan motif yang spesifik dengan daerah tersebut, dan dikenal sampai sekarang sebagai motif-motif Sungayang, motif Koto Gadang dan lain-lain.

\section{Bahan Baku}

Pada masa dahulu, penyiapan bahan baku tenun seperti benang dan pewarnaannya dikerjakan dengan bahan-bahan yang diambil dari alam. Akan tetapi sekarang digunakan benang katun dan rayon hasil pabrik dan pewarnaan menggunakan bahan kimia meskipun masih dikerjakan secara manual. Pekerjaan ini menjadi komoditas masyarakat Silungkang. Adapun benang mas yang biasa disebut makau adalah produk industri rumah tangga dari India dan didatangkan melalui Singapura.

Bahan baku benang ini dipersiapkan untuk ditenun oleh perajin Silungkang. Benang lungsin jumlahnya mencapai 2000 lembar untuk membuat satu helai kain sarung, dan panjangnya mencapai 14 meter, cukup untuk membuat beberapa helai kain. Setiap helai benang secara bergantian masuk ke dalam sepasang karok dan terus melewati gigi-gigi suri hingga dieratkan dengan menggunakan beberapa batang lidi. Pekerjaan persiapan ini dinamakan ma-anyi. Benang pakan yang berupa katun atau rayon, juga benang mas, digulung oleh masing-masing penenun sendiri pada kasali dari bambu menggunakan alat yang dinamakan kincia tanun. 


\section{Alat Tenun}

Tenun songket Pandai Sikek seluruhnya dikerjakan dengan tangan, mengunakan alat-alat tradisional yang umumnya terbuat dari bahan alam seperti kayu dan bambu (Gambar 1). Hampir tidak ada digunakan bahan logam seperti besi. Alat utama dinamakan panta adalah sebuah konstruksi kayu berukuran 2 x 1.5 meter tampat merentangkan benang yang akan ditenun. Benang dasar yang dinamakan lungsin atau lusi, juga disebut tagak kalau di Pandai Sikek ini adalah cadangan benang yang digulung pada gulungan dan terpasang pada arang babi di bagian yang jauh dari panta. Wanita yang mengerjakan tenun ini duduk pada semacam bangku di bagian pangkal dari panta ini. Di depannya ada dua buah tiang yang menyangga kayu paso tempat kain yang sudah ditenun akan digulung. Jadi lungsin terentang antara gulungan dengan paso dan di antaranya terdapat satu pasang karok dan satu buah suri tergantung pada tandayan. Di kiri dan kanan penenun digantungkan tempat penyimpan skoci benang pakan dan skoci benang mas. Skoci ini dinamakan turak dan terbuat dari bambu.
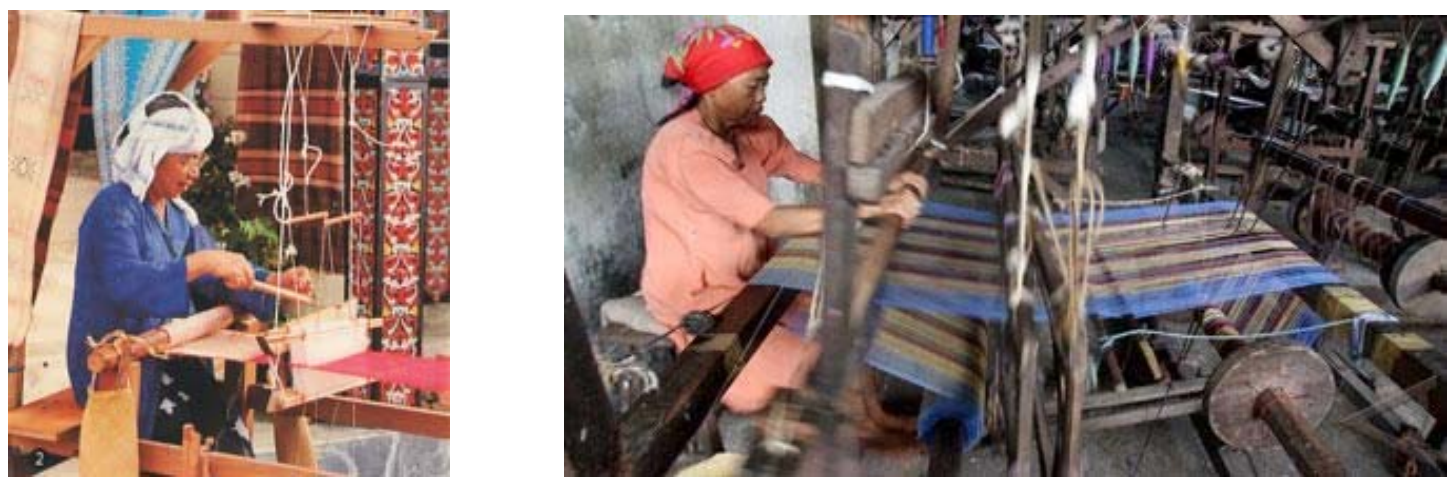

Gambar 1 Alat Tenun Traditional

Bergulirnya roda waktu, dimana kemajuan teknologi semakin berkembang, kini hadir penemuan terbaru alat tenun modern kecepatan tinggi yang telah dikontrol dengan komputer dengan hasil kain bergambar (Gambar 2). Mesin tenun ini merupakan hasil penemuan dan pengembangan dari Sakichi Toyoda yang telah menghabiskan umurnya untuk menemukan mesin pintal. Hasl penemuan tersebut kini diproduksi oleh putra tertuanya Kiichiro Toyoda pendiri Toyota Motor Coorporation (TMC).

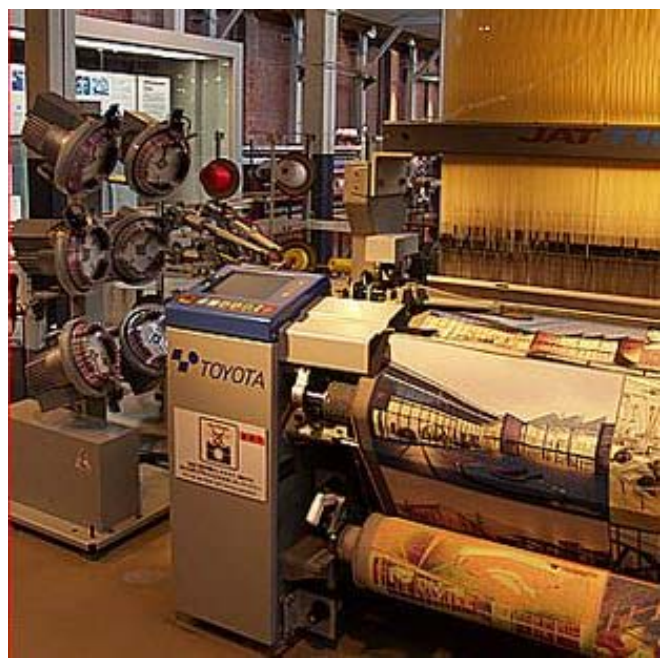

Gambar 2 Alat Tenun Modern 


\section{Tipe Kain Tenun}

Secara teknis pembuatan kain tenun Pandai Sikek, tipe kain terbagi kepada dua tipe, yaitu balapak dan bacatua. Kain balapak adalah kain yang ditenun dengan melawatkan benang mas pada seluruh bidang kain, sedang kain bacatua adalah kain yang sebagian besar terdiri dari tenunan lungsin dengan pakan saja, dan hanya pada bagian-bagian tertentu diberi hisasan benang mas sehingga bahannya menjadi lebih ringan.

Dalam pembuatan motif menggunakan benang mas, dikenal istilah tuhuak, yaitu jumlah beberapa kali benang mas dilewatkan pada jalur motif yang sama. Kalau ada enam lembar benang mas pada jalur yang sama akan memberikan kesan kasar, sedang kalau hanya dua lembar akan menghasilkan motif yang lebih halus.

Tipe kain juga ditentukan kegunaannya oleh pemesan. Kain yang ditenun untuk dipakai pada upacara perkawinan adalah berbeda dari kain yang ditenun untuk dipakai pada acara resepsi. Bahan yang digunakan, seperti banang katun, rayon, sutra alam, benang mas atau benang perak, turut menentukan tipe kain tenun yang dihasilkan. Selain itu, dalam merancang suatu produk tenunan akan sangat memperhatikan motif-motif yang sesuai dengan karakter kain yang diinginkan.

\section{Motif Kain Tenun}

Motif kain disebut juga cukie bagi penenun di Pandai Sikek, yakni sebuah pola yang mengisi bagian-bagian dari kain. Misalnya: cukie tertentu dipilih untuk badan kain, cukie lainnya untuk kepala kain dan tapi atau pola pinggir kain, dan ada beberapa motif lainnya lazim digunakan untuk biteh yang membatasi antara beberapa motif. Sedangkan yang disebut motif Sungayang adalah corak keseluruhan kain. Contoh motif kain tenun keseluruhan (Gambar 3), motif tenun hias pinggir (Gambar 4).
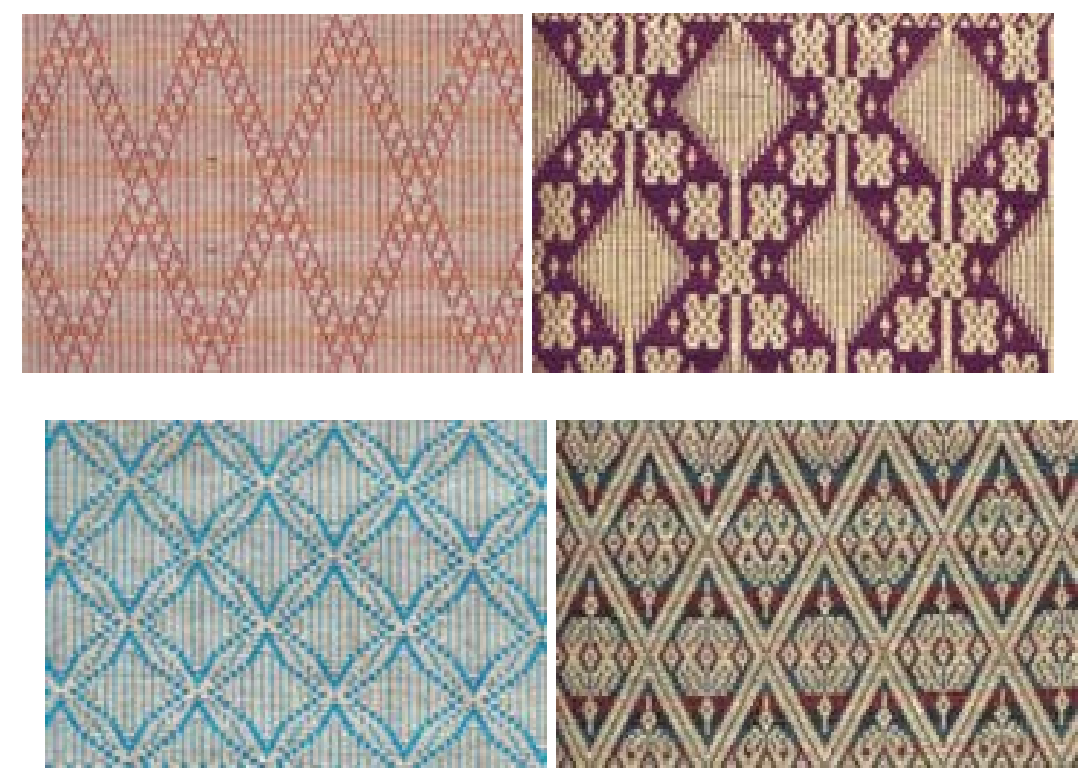

Gambar 3 Contoh Motif Kain Tenun Keseluruhan: Saik Kalamai (Kiri Atas), Buah Palo (Kanan Atas), Balah Kacang (Kiri Bawah), dan Simasam (Kanan Bawah) 

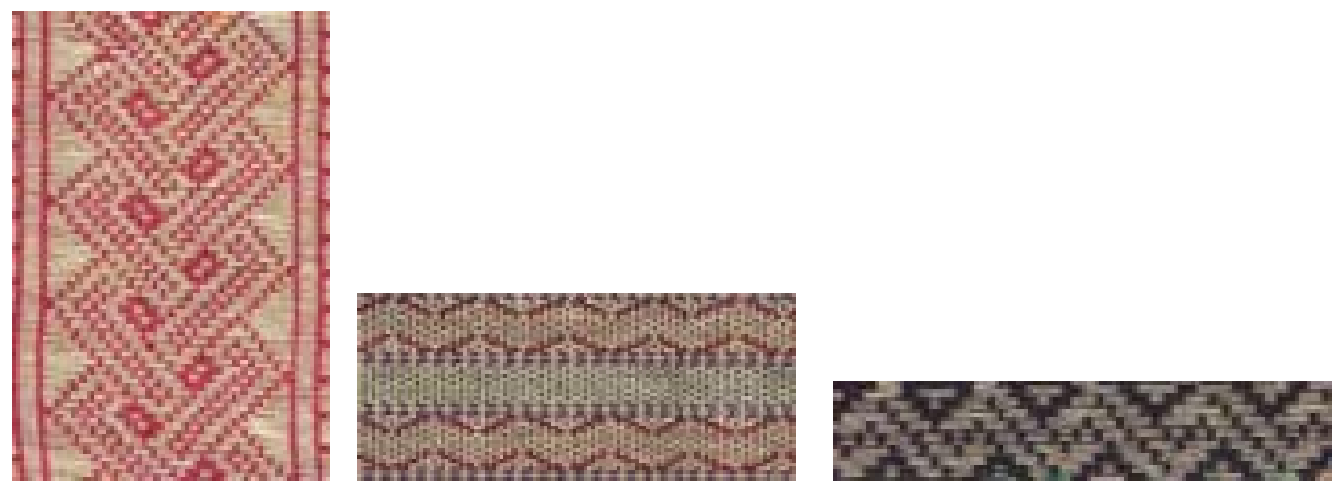

Gambar 4 Contoh Motif Tenun Hias Pinggir: Saluak Laka (Kiri),

Ulla Gerang (Tengah), dan Itiak Pulang Patang (Kanan)

Beberapa nama yang pada mulanya janggal dimaksudkan hanya untuk sementara tetapi kemudian bertahan di kalangan sebagian perajin tenun (Gambar 5).
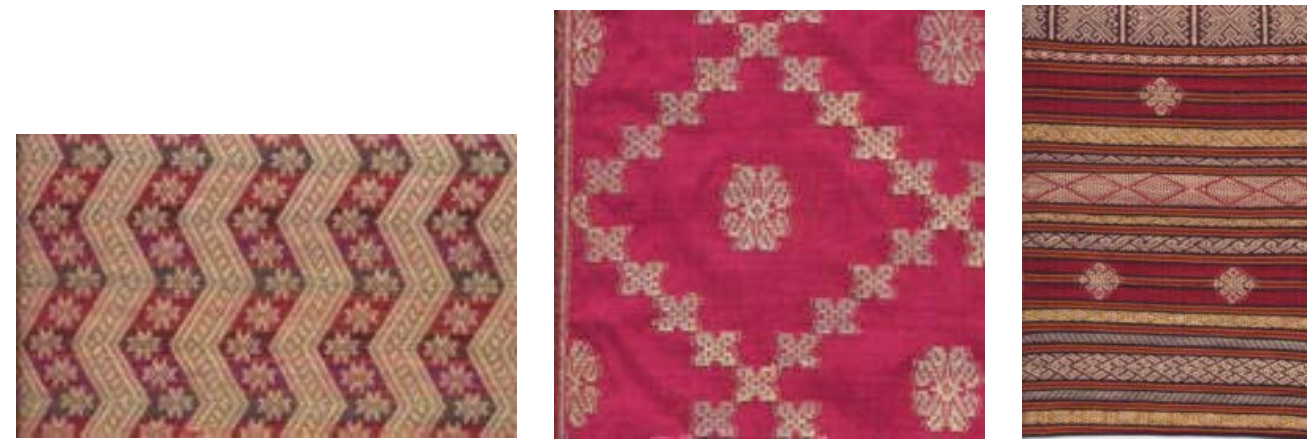

Gambar 5 Contoh Motif Tenun dengan Nama Janggal:

Zigzag Tirai (Kiri), Kali-Kali (Tengah), dan Liris-Liris (Kanan)

\section{Penerapan Kain Tenun pada Perencanaan Desain Interior}

Dari sejak dahulu kala, kain tenun sudah menjadi salah satu unsur estetika pada perencanaan Desain Interior dengan cara dipajang pada seutas tali yang direntangkan diantara tiang-tiang utama rumah yang baru melaksanakan upacara batagak rumah gadang. Penerapan kain tenun pada perencanaan interior juga sudah kian menyatu dengan elemen-elemen interior yang ada seperti lantai, dinding, ceiling, dan furniture. Hal ini berperan baik dari segi fungsi dan juga estetika. Namun sangat disayangkan penggunaan ini tidak berkembang luas di kalangan masyarakat (belum memasyarakat). Salah satu faktornya dapat disebabkan karena lamanya proses pembuatan kain tenun sehingga menyebabkan tingginya harga dari nilai jual kain tenun tersebut.

Sejalan dengan perkembangan waktu yang ada, dimana kemajuan teknologi sudah semakin pesat serta meningkatnya taraf kehidupan manusia di Indonesia, maka sudah ditemukan teknologi terbaru sistem komputerisasi dengan kecepatan yang tinggi dalam menghasilkan kualitas kain tenun yang baik. Selain itu peningkatan kualitas dan kuantitas dengan penggunaan alat tenun tradisional juga sudah semakin terjamin dengan adanya wadah-wadah yang menaungi kelompok masyarakat dalam membuat kain tenun. Kain tenun kini sudah semakin dikenal baik oleh masyarakat Indonesia ataupun oleh masyarakat luar negeri, khususnya untuk memperkenalkan warisan budaya dalam negeri yang memiliki nilai yang tinggi untuk dilestarikan dan dikembangkan. 
Seperti salah satu contohnya acara exhibition yang diadakan oleh sebuah wadah Cita Tenun Indonesia (CTI), dimana organisasi ini bertujuan untuk menjaga dan melestarikan keberadaan tenun serta memasyarakatkan kembali penggunaannya.

Acara yang diadakan di Rich Carlton, Pacific Place pada tanggal 27-29 Agustus 2010 disemarakkan oleh 13 karya Desainer Interior HDII, yang menerapkan kain tenun pada perencanaan interior dengan tema rumah tinggal. Penerapan kain tenun dapat diaplikasikan sebagai elemen-elemen pada interior seperti lantai, dinding, ceiling, serta penerapan fabrik pada furniture. Dalam pengaplikasiannya kain tenun yang dikenal masyarakat memiliki nilai budaya Indonesia serta nilai jual yang tinggi ini, diterapkan dengan kombinasi gaya dan material pendukung lain sehingga dapat melahirkan suatu hibriditas desain yang memiliki esensi/nilai yang dapat menunjang keutuhan karyakarya Desainer Interior tersebut demi memperluas pangsa pasarnya.

Gambar 6 hingga 12 menunjukkan dokumentasi 13 karya Desainer Interior HDII tersebut.
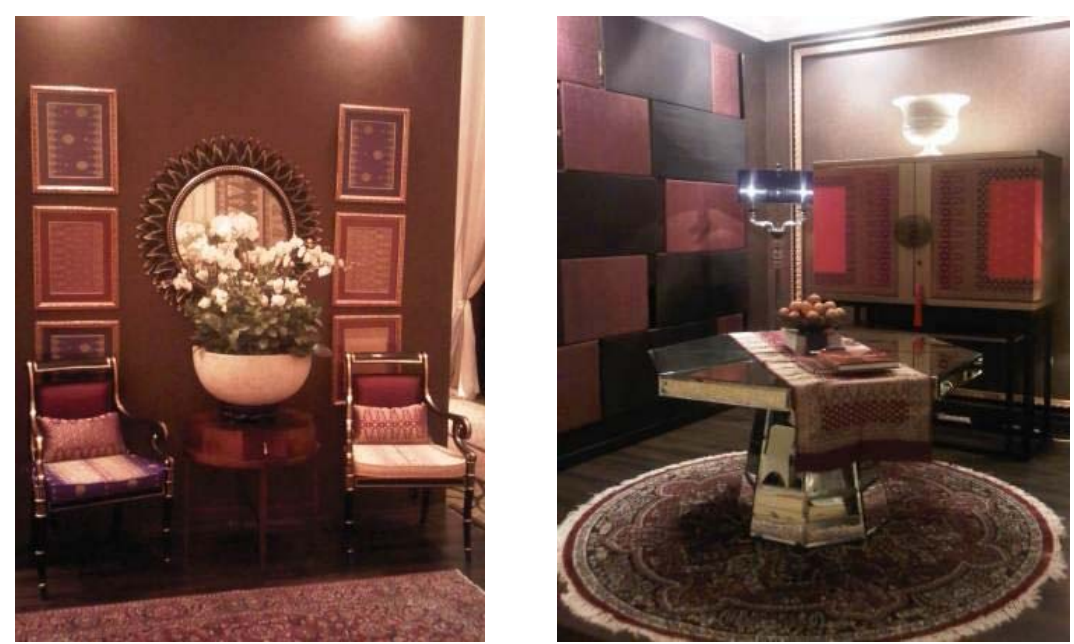

Gambar 6 Foyer - Sammy Hendramianto,

” A Touch of Songket Palembang in my Foyer”, Kain Songket Palembang
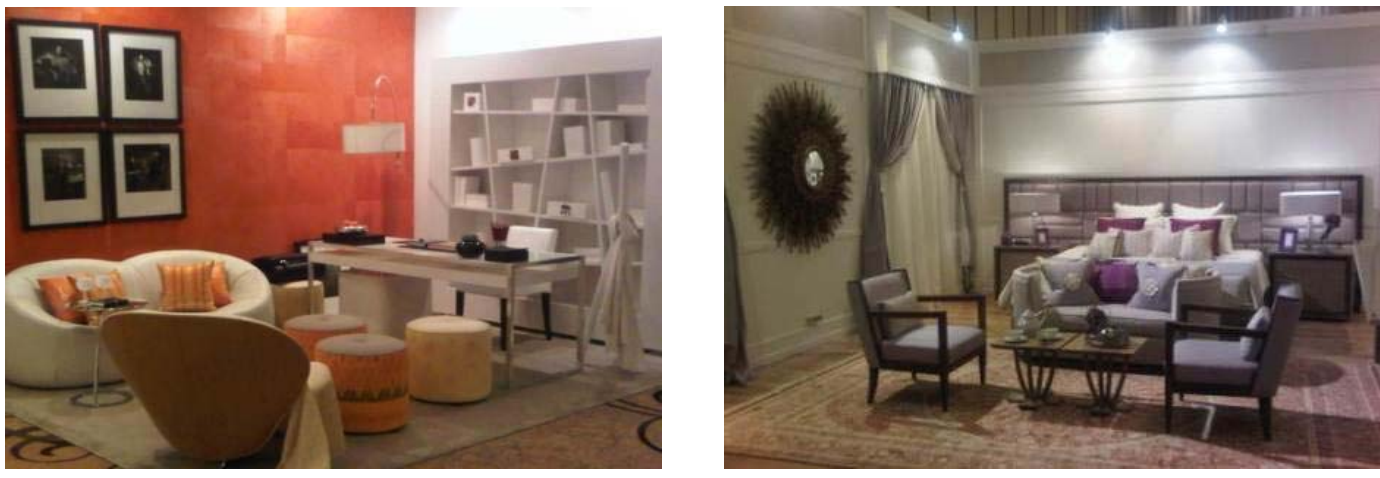

Gambar 7 Kiri: Working Room - Yuni Jie, ”Inspirelab”, Kain Songket Padang,

Tenun Garut, Tenun Majalaya dan Tenun Bali,

Kanan: Master Bedroom - Andi Lim,’Sriwijaya Return”,

Kain Tenun dan Songket Palembang 

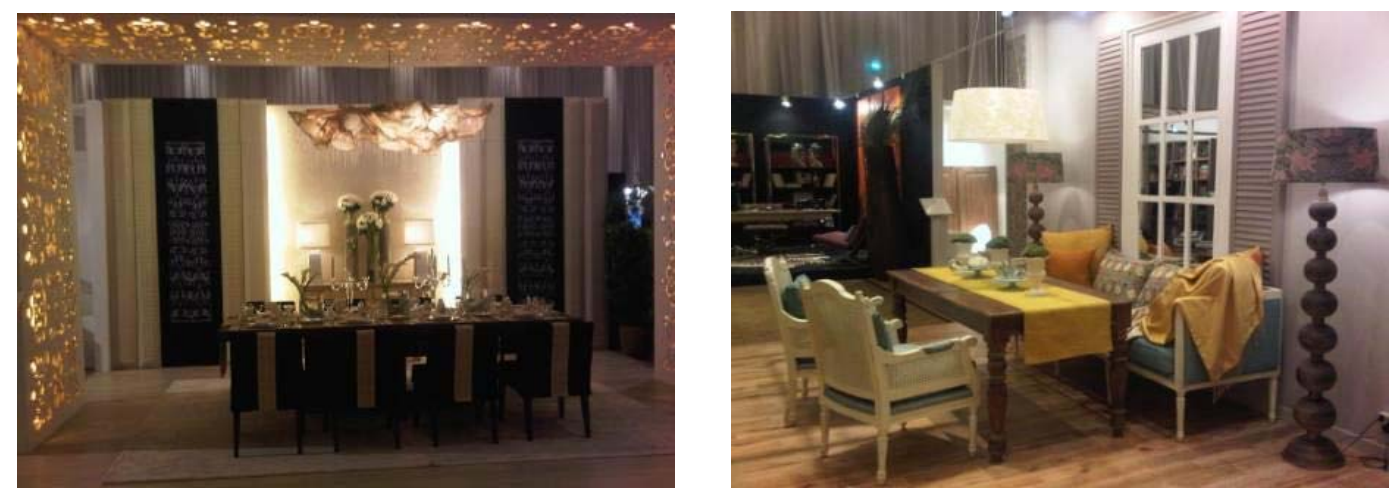

Gambar 8 Kiri: Dining Room - Joke Roos, ”Elok Mempesona”, Kain Songket Palembang, Tenun Majalaya, Tenun NTT dan Tenun Garut.

Kanan: Pantry - Fifi Fimandjaja, "Morning Glory",

Kain Tenun Bali, Tenun Garut dan Tenun Makassar
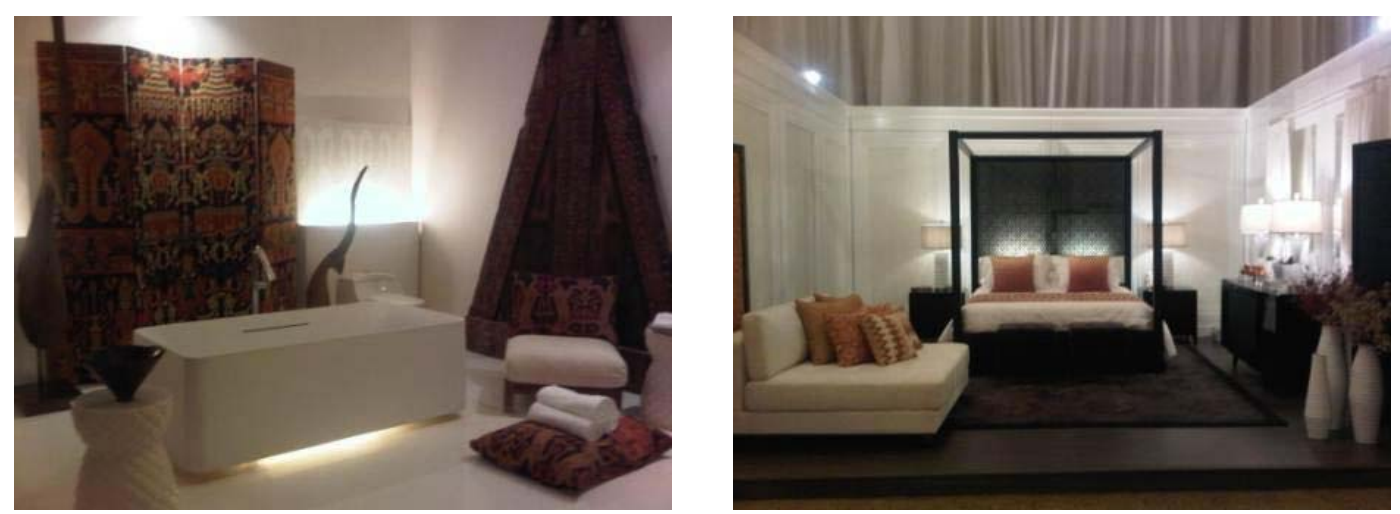

Gambar 9.Kiri: Bathroom - Ary Juwono, ”Gorgeous Tribal Sumba", Kain Tenun NTT. Kanan: Master Bedroom - Anita Boentarman, "The Luxury of Simplicity", Kain Tenun Pekalongan, Tenun Bali, Tenun Garut dan Tenun Makassar
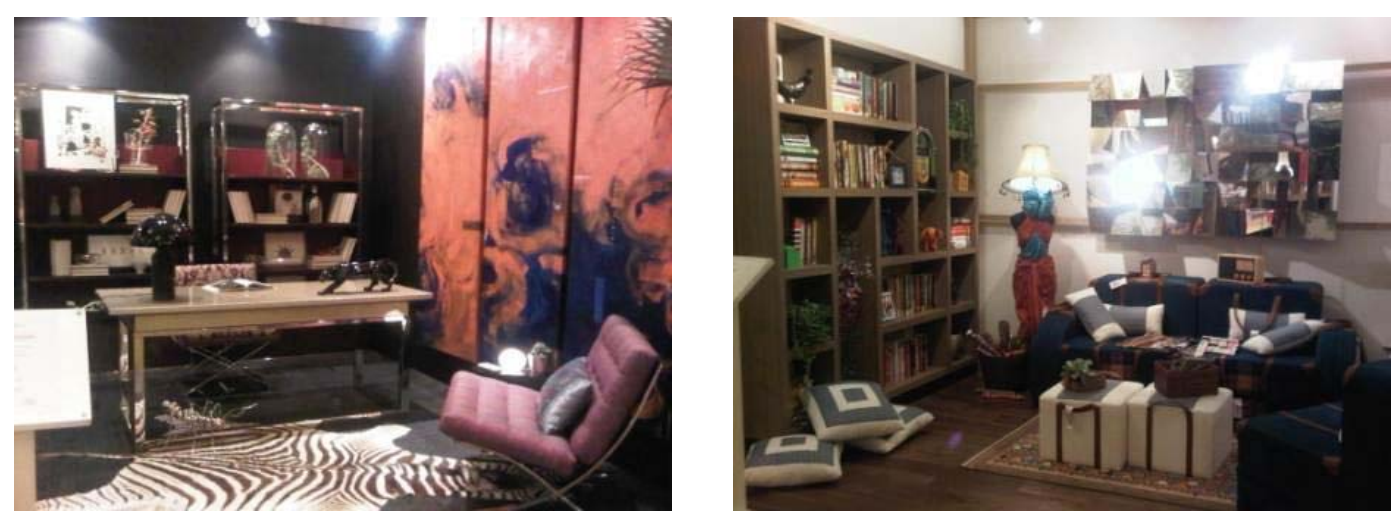

Gambar 10. Kiri: Working Room - Prasetio Budhi, ”Romantisme Kekinian”, Songket Sutra, Songket Bali, Tenun Sutera Garut dan Hem Tenun Garut. Kanan: Playroom - Bobos, ”Remaja dan Warna”, Kain Tenun Palembang, Tenun Majalaya, Tenun Lurik Yogya dan Tenun Makassar 

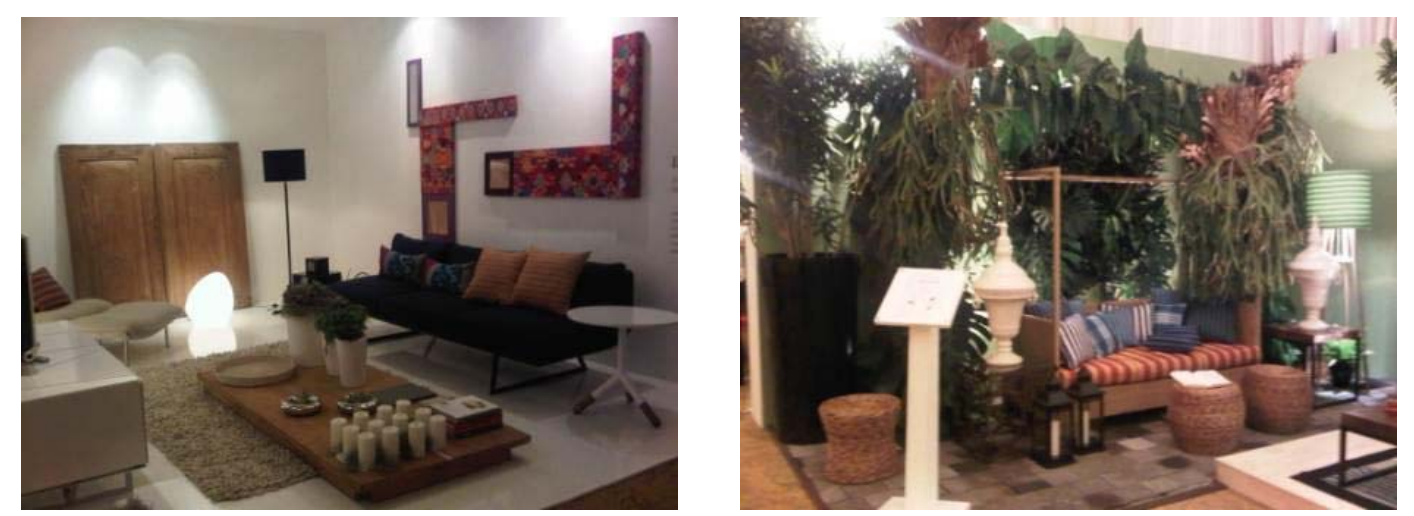

Gambar 11 Kiri: Living Room - Eko Priharseno, ”Urban Meets Traditional”,

Kain Tenun Songket Bali, Tenun Garut dan Kain Endek Polos.

Kanan: Backyard - Roland Adam, ”From Sultra with Love”,

Kain Tenun Sulawesi Tenggara dan Tenun Garut
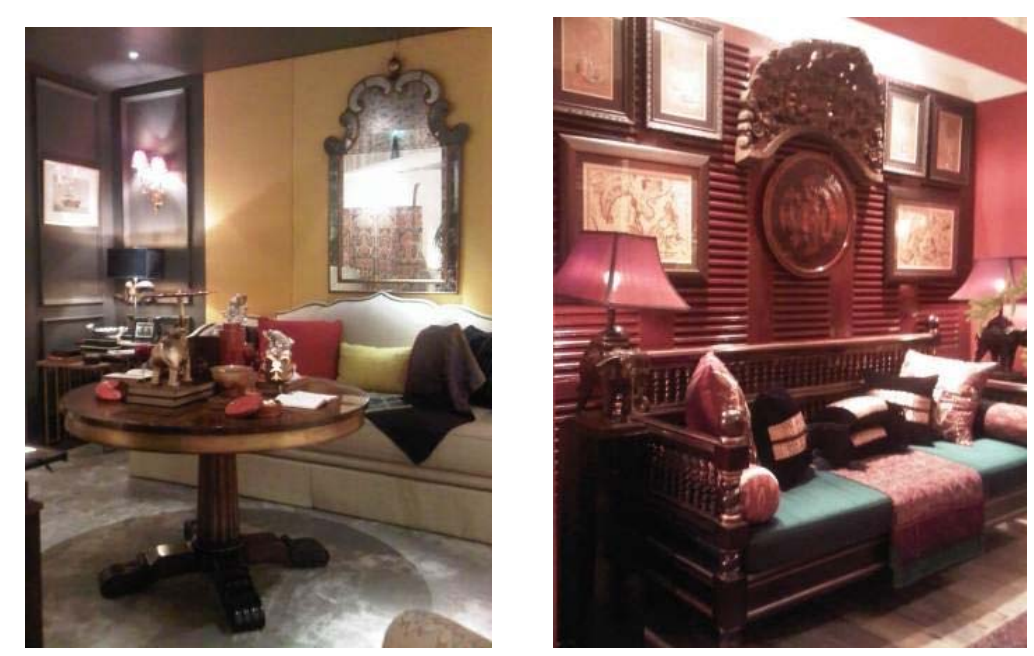

Gambar 12 Kiri: Living Room - Shirley Gouw, ”Tenun in Your Living Room”,

Kain Tenun Garut, Tenun Majalaya dan Tenun Makassar.

Kanan: Foyer - Agam Riadi, ”A Journey of Limar”,

Kain Tenun Songket Limar Palembang dan Ikat Bali

\section{PENUTUP}

Keberadaan tenun di Indonesia memberi warna tersendiri bagi kekayaan budaya bangsa (local content). Kain tenun tidak hanya sebagai aset, tetapi juga memiliki potensi sebagai sumber devisa negara. Potensi tersebut muncul, mengingat kain tenun sekarang tidak hanya sekadar menjadi simbol adat. Kain tenun telah menjadi produk modern, tidak lagi menjadi bahan yang bersifat konvensional. Tenun merupakan salah satu sarana seni yang patut dilestarikan. Mengikuti jejak batik, wayang dan, keris, tenun pun ingin mendapatkan pengakuan dari UNESCO sebagai warisan budaya tak benda dunia. Hal ini dilakukan mengingat pentingnya pengakuan dari masyarakat dunia atas tenun, agar tidak diserobot oleh bangsa lain. 
Berbagai usaha telah dilakukan terutama oleh Cita Tenun Indonesia (CTI) sebagai perintis dimana sebagai langkah awal telah meluncurkan buku berbahasa Inggris "Tenun: Handwoven Textile of Indonesia" untuk memperkenalkan tenun Indonesia kepada masyarakat dunia. Apalagi perkembangan jaman sangat mendukung dan memudahkan manusia untuk berkreasi. Maka dari pada itulah, Cita Tenun Indonesia aktif mengadakan beberapa acara dengan menggandeng beberapa aspek desain seperti contohnya desain fashion dan interior dalam menerapkan kain tenun disetiap elemen desainnya. Hal ini dilakukan sebagai bentuk pelestarian tenun agar tidak langka dan punah serta memasyarakatkan tenun agar menjadi bagian dari warisan budaya Indonesia.

Diharapkan dengan dikenal dan dipergunakannya tenun dalam beberapa aspek kehidupan, dapat meningkatkan dan mengembangkan produksi tenun serta pemasarannya. Dimana hal ini dapat memperluas pasar baik di dalam negeri dan mancanegara dan menjadikan Indonesia sebagai sentra pasar Tenun. Selain itu, penerapan tenun pada Desain Interior juga diharapkan dapat memberikan kontribusi nilai jual yang tinggi untuk setiap pengaplikasiannya dimana dalam hal ini mengangkat warisan budaya (local content) Indonesia yang sarat kaya akan sejarah, sehingga kualitas anak negeri dalam hal ini Desainer Interior Indonesia dapat melahirkan karya-karya yang berkualitas dan bernilai jual tinggi baik di dalam negeri maupun mancanegara.

\section{DAFTAR PUSTAKA}

Anwar, An. (2003). Rumah Tenun Pusako. Diakses dari http://www.angelfire.com/id/pusako/songket.htm\#TOP

BJ, Zulkifli. (2010). Musium Toyota: Dari Mesin Tekstil ke Mobil - Bagian 1. Diakses dari http://otomotif.kompas.com/read/2010/11/10/06545066/Musium.Toyota.Dari.Mesin.Tekstil.ke .Mobil.-.Bagian.1

Kartiwa, S. (1986). Kain Songket Indonesia. Jakarta: Djambatan.

Kartiwa, S. (1987). Tenun Ikat-Indonesian Ikats. Jakarta: Djambatan.

Koentjaraningrat. (1995). Manusia dan Kebudayaan di Indonesia. Jakarta: Djambatan..

Richter, A. (1993). Arts and Crafts of Indonesia. California: Chronicle Books. 